\title{
Pengaruh Pemberian Plyometric Training Depth Jump Terhadap Tinggi Lompatan Vertical Jump Pada Pemain Bola Voli
}

\author{
Wahyuni $^{1 *}$, Nur'alif Kukuh Ardian ${ }^{2 *}$, Salma Muazarroh ${ }^{3 *}$ \\ ${ }^{123 *}$ Fisioterapi/Fakultas Ilmu Kesehatan, Universitas Muhammadiyah Surakarta \\ Jl. A Yani, Tromol Pos I, Pabelan, Surakarta, Jawa Tengah, Indonesia \\ *Email: wahyuni@ums.ac.id; nuralifkukuh@gmail.com; salma.azza@gmail.com
}

Tanggal Submisi: 10 Maret 2021; Tanggal Penerimaan: 17 November 2021

\begin{abstract}
ABSTRAK
Latar Belakang: Olahraga dapat meningkatkan kebugaran dan menjaga kesehatan, serta menjadi sarana pengembangan diri atau individu melalui prestasi yang diperoleh dari setiap cabang olahraga tertentu. Di Indonesia dikenal berbagai cabang olahraga seperti sepak bola, bola basket, bola voli, bulu tangkis. Salah satu olahraga yang digemari masyarakat Indonesia adalah bola voli, Menurut Federasi Bola Voli internasional, di seluruh dunia ada sekitar 500 juta orang bermain bola voli. Ada beberapa teknik dalam permainan yang harus dikuasai oleh seorang atlit, yaitu servis, passing, smash dan block. Smash dan blok didominasi oleh gaya lompatan vertikal pemain yang biasanya menjadi poin kunci kemenangan dalam permainan bola voli. Tujuan: Untuk mengetahui pengaruh latihan pliometrik depth jump terhadap lompatan vertikal pada pemain bola voli. Metode: Jenis penelitian ini menggunakan metode eksperimen semu dengan desain penelitian pre and post test with control group. Banyaknya sampel dalam penelitian ini adalah 20 orang, Teknik pengambilan sampel menggunakan purposive sampling yang dipilih berdasarkan kriteria inklusi dan eksklusi. Sampel dibagi menjadi dua kelompok yaitu kelompok perlakuan dan kelompok kontrol secara acak, dan diukur tinggi lompatan pada masingmasing kelompok sebelum dan sesudah diberikan perlakuan latihan plyometric dept jump. Hasil: Hasil penelitian menunjukkan pengaruh latihan lompat kedalaman plyometric terhadap ketinggian lompat vertikal. Rata-rata tinggi lompatan meningkat dari $44,3 \pm 3,23$ menjadi $51,2 \pm 3,36$ pada kelompok perlakuan. Sementara pada kelompok kontrol terjadi peningkatan dari $41 \pm 2,58$ menjadi $44,2 \pm 2,97$. Hasil uji pengaruh pada kelompok perlakuan maupun kelompok kontrol menunjukkan nilai yang signifikan $(\mathrm{P}<0,005)$. Hasil uji beda pengaruh, terdapat beda pengaruh antara kelompok perlakuan dan kelompok control dalam peningkatan lompatan vertikal. Kesimpulan: Latihan pliometrik dept jump berpengaruh terhadap tinggi lompatan pemain bola voli. Tinggi lompatan ini bisa digunakan sebagai modal bagi pemain untuk memberikan permainan terbaiknya, sehingga tercapai kemenangan.

Kata Kunci : bola voli, latihan pliometrik dept jumpa, lompatan vertikal
\end{abstract}

\section{ABSTRACT}

Background: Sport can improve and maintain health, as well as become a means of selfdevelopment or individual achievement obtained from each particular sport. In Indonesia, there 
are various sports such as football, basketball, volleyball, badminton. One of the most popular sports in Indonesia is volleyball. According to the International Volleyball Federation, around 500 million people worldwide play volleyball. There are several techniques in the game that must be mastered by an athlete, namely serving, passing, smash, and block. Smash and block are dominated by the player's jumping style which is usually the key point of victory in volleyball games. Objective: To determine the effect of depth jump plyometric training on vertical jumps in volleyball players. Methods: This type of research uses a quasi-experimental method with a pre and post-test research design with a control group. The number of samples in this study was 20 people. The sampling technique used purposive sampling which was selected based on inclusion and exclusion criteria. The sample was divided into two groups, namely the treatment group and the control group at random, and the vertical jump of each group was measured before and after being given the plyometric dept jump exercise. Results: The results showed the effect of the plyometric depth jump exercise on the vertical jump height. The average jump height increased from $44.3 \pm 3.23$ to $51.2 \pm 3.36$ in the treatment group. Meanwhile in the control group there was an increase from $41 \pm 2.58$ to $44.2 \pm 2.97$. The results of the influence test in the treatment group and control group showed a significant value $(P<0.005)$. The results of the effect test, there was an influence between the treatment group and the control group in increasing the vertical jump. Conclusion: Dept jump plyometric exercise has an effect on the jump height of volleyball players. This jump height can be used as capital for players to give their best game, so that victory is achieved.

Keyword : volley ball, plyometric dept jump, vertical jump

ISSN 1979-7621 (Print). ISSN 2620-7761 (Online).

DOI $10.23917 / j k . v 14 i 2.12924$

\section{PENDAHULUAN}

Di Indonesia terdapat berbagai olahraga yang dikenal seperti sepakbola, basket, voli, bulutangkis dll. Salah satu olahraga yang digemari masyarakat di Indonesia adalah olahraga bola voli, perkiraan dari federation international de volley bahwa 500 juta orang bermain bola voli diseluruh dunia (Eerkes, 2012). seringkali kita menemukan permainan bola voli di lingkungan rumah, sekolah-sekolah atau pun di klub-klub voli. Indonesia sendiri selalu mengikut sertakan klub voli dalam ajang kejuaraan yang diselengarakan di dalam negeri maupun antar negara dengan tujuan agar permainan bola voli di Indonesia mampu bersaing dengan bangsa lain. Prestasi voli Indonesia pada kejuaraan bola voli internasional pernah menjadi juara pada 2018, meskipun menjadi juara masih ada kelemahan yang terlihat khusunya pada bagian service, smash dan block karena masih sering terbaca dan kurang optimal dalam mengantisipasi smash yang dilakukan lawan. Dari identifikasi masalah yang dilakukan peneliti, latihan sebagai upaya untuk meningkatkan prestasi pada pemain bola voli. Salah satu kemampuan pemain yang harus dimiliki dalam meningkatkan prestasi pada permainan bola voli dengan menguasai teknik melompat sebagai salah satu faktor yang penting. Bisa dilihat saat pemain melakukan smash ke arah lawan, maupun blocking bola untuk bertahan dari serangan lawan sangat rendah tinggi lompatan yang terlihat dan kurang optimal.

Oleh sebab itu peneliti akan melakukan penelitian tentang Pengaruh pemberian latihan plyometric training depth jump terhadap kemampuan vertical jump pada pemain bola voli. Sehingga kedepannya dari hasil variasi latihan yang diberikan diatas dapat dijadikan sebagai referensi gambaran intervensi yang tepat dan efektif bagi pelatih dan pemain bola voli.

\section{METODE PENELITIAN}

Jenis penelitian yang digunakan adalah quasi exsperimental. Desain penelitian ini menggunakan pre-test and post-test with control 
group design, untuk mengetahui manfaat latihan plyometric training depth jump terhadap tinggi lompatan vertical jump pemain bola voli . Dalam desain penelitian ini terdapat 2 kelompok yaitu kelompok perlakuan dan kelompok control. Penelitian ini akan dilakukan di Gelanggang Olaraga Kabupaten Sragen, Jawa tengah dan dilaksanakan selama 4 minggu dengan 3 kali latihan dalam seminggu pada bulan Desember 2019. Populasi dalam penelitian ini adalah para pemain bola voli POPSI kabupaten Sragen yang bergabung dan berlatih aktif berjumlah sekitar 30 orang. Teknik pengambilan sampel dalam penelitian ini menggunakan teknik purposive samply dimana pengambilan sampel berdasarkan kriteria inklusi, kriteria eksklusi, dan kriteria drop out. Besar sampel pada penelitian ini adalah 20 orang terbagi dalam 2 kelompok, yaitu 10 sampel kelompok perlakuan, 10 sampel kelompok kontrol. Variabel bebas dalam penelitian ini adalah Plyometric Training dan Variabel terikat dalam penelitian ini adalah Peningkatan tinggi lompatan Vertical Jump pada peman voli.

\section{HASIL DAN PEMBAHASAN}

Tabel 1 menunjukkan karakteristik responden berdasarkan umur dan nilai vertical jump. Jumlah responden adalah 20 orang, yang dibagi secara random menjadi dua kelompok, yaitu kelompok perlakuan dan kontrol. Berdasarkan data yang didapatkan gambaran usia terendah yaitu 13 tahun dan 14 tahun usia tertinggi. Dari nilai vertical jump, didapatkan hasil terbanyak pada $41-50 \mathrm{~cm}$.

Tabel 1 Karakteristik Responden

\begin{tabular}{llcccc}
\hline \multirow{2}{*}{ Karakteristik } & \multicolumn{2}{c}{ Perlakuan } & \multicolumn{2}{c}{ Kontrol } \\
& Sub-grup & Pre & Post & Pre & Post \\
\hline Umur (th) & 13 & $3(30 \%)$ & & $5(50 \%)$ & \\
& 14 & $7(70 \%)$ & & $5(50 \%)$ & \\
$X^{2}$ & & 13,70 & & 13,50 & \\
Vertical jump & $31-40$ & 1 & 0 & 2 & 1 \\
(cm) & $41-50$ & 9 & 5 & 8 & 9 \\
& $51-60$ & 0 & 5 & 0 & 0 \\
$\mathrm{X}^{2} \pm$ SD & & $44,3 \pm 3,23$ & $51,2 \pm 3,36$ & $41 \pm 2,58$ & $44,2 \pm 2,97$ \\
\hline
\end{tabular}

Dari data usia tersebut menurut (Eckert \& Snarr, 2015), latihan plyometric training depth jump memiliki efek positif pada usia 10-13 tahun membantu mengembangkan daya dan kecepatan, namun sebaiknya dilakukan dengan memulai dengan 1-3 set terlebih dahulu. Adapun pendaratan atau kontak pendaratan pengulangan melompat menjadi acuan dalam performa atlet, dianjurkan bahwa atlet tidak melakukan lebih dari jumlah kontak pendaratan yang disarankan dengan rentang usia yaitu : 14-17 tahun sebesar 80-100 kali kontak darat.

Tabel 2 Hasil uji normalitas Shapiro Wilk Test

\begin{tabular}{llccc}
\hline Kelompok & & Statistic & $D f$. & Sig. \\
\hline \multirow{2}{*}{ Intervensi } & Pre test &, 971 & 10 &, 903 \\
& Post test &, 858 & 10 &, 072 \\
\multirow{2}{*}{ Kontrol } & Pre test &, 885 & 10 &, 147 \\
& Post test &, 938 & 10 &, 528 \\
\hline
\end{tabular}


Tabel 2, menunjukkan hasil uji normalitas data. didapatkan nilai uji normalitas menggunakan Shapiro wilk test pada persentase tinggi lompatan menggunakan vertical jump test pada kelompok intervensi saat pre test adalah $0,903 \mathrm{p}>0,05$ dan pada saaat post test adalah $0,072 \mathrm{p}>0,05$ maka data berdistribusi normal. Sedangkan hasil uji normalitas pada kelompok kontrol pre test adalah $0,147 \mathrm{p}>0,05$ dan pada saat post test adalah $0,528 \mathrm{p}>0,05$ maka data berdistribusi normal

Tabel 3 Uji Statistik

\begin{tabular}{lccc}
\hline Uji statistik & Kelompok & $\mathrm{X}^{2}$ & P-value \\
\hline Paired Sample t Test & Intervensi & 51,20 & 0,001 \\
& Kontrol & 44,20 & 0,001 \\
Independent t-test & Intervensi- Kontrol & 0,001 \\
\hline
\end{tabular}

Uji pengaruh menggunakan

analisa data Paired sample $t$ Test didapatkan hasil pada tabel 3 bahwa p (value) pada kelompok intervensi dan kelompok kontrol adalah $0,00 \mathrm{p}<0,05$. Hal ini berarti terdapat pengaruh pada kelompok intervensi.

Dari data tabel 3 juga didapatkan hasil uji beda pengaruh antara kelompok intevensi dan kelompok kontrol diperoleh hasil 0,00 p < 0,05 sehingga dapat disimpulkan terdapat perbedaan hasil tinggi vertical jump antara kelompok intervensi dan kelompok kontrol.

Berdasarkan uji analisa pada tabel 3 dan didapatkan hasil diperoleh data nilai latihan depth jump memiliki pengaruh yang dibuktikan dengan data nilai $0,00<0,05$, karena $\mathrm{p}<0,05$ maka Ha diterima dan Ho ditolak, dimana artinya terdapat pengaruh dari latihan plyometric training depth jump terhadap peningkatan vertical jump pemain voli. Depth jump adalah latihan plyometric dengan intensitas tinggi yang dirancang untuk meningkatkan kekuatan otot dan efisiensi kekuatan di ektermitas bawah. Merupakan salah satu bentuk latihan berguna untuk meningkatkan performa tinggi lompatan dengan melatih kekuatan otot tungkai, paha dan punggung bagian bawah sehingga gerakan ini dapat memberi manfaat peningkatan kinerja atletik dan mencegahan terjadinya cedera (Eckert \& Snarr, 2015).

Depth jump diawali dengan seseorang melangkah dari media berupa box atau meja kotak setinggi $25-80 \mathrm{~cm}$, kemudian dilanjutkan dengan melompat keatas dengan cepat (Singh \& Singh, 2012). Depth jump menggunakan prinsip plyometric training yaitu stretch shortening cyle (SSC) dimana kekuatan otot yang dihasilkan dengan maksimal pada waktu yang singkat secara cepat dapat menghasilkan kontraksi dan rileksasi otot sehingga membuat otot menjadi elastis dan respon propioseptif sendi terstimulus saat bergerak melompat (Khlifa et al., 2010).

Berdasarkan uji analisa dan didapatkan hasil pada tabel 4.5 uji beda pengaruh antara kelompok intervensi dan keloompok kontrol menggunakan independent sample $t$ test didapatkan hasil nilai $p$ (value) 0,00 yang berarti data $\mathrm{p}<0,05$ maka $\mathrm{Ha}$ diterima dan Ho ditolak yang artinya terdapat perbedaan pengaruh signifikan antara kelompok intervensi dan kelompok control, dimana penambahan latihan plyometric training depth jump memberikan pengaruh lebih baik terhadap tinggi vertical jump dari pada hanya latihan konvensinal. Hal ini terjadi karena depth jump melatih kekuatan otot yang terdiri dari Gluteus maximus, gluteus medius, quadriceps (rectus femoris, vastus lateralis, vastus intermedius, vastus medialis), hamstrings (biceps femoris, semitendinosus, semimembranosus) otot utama dan otot lain: otot otot adductor dan calf muscle (soleus, gastrocnemius) secara efektif untuk peningkatan kemampuan dan kinerja otot saat melakukan vertical jump (Arazi, et al., 2014).

Berdasarkan analisa modifikasi depth jump yaitu hip depth jump memberikan kontribusi sendi hip $80 \%$, pada sendi knee $5 \%$ dan sendi ankle $15 \%$, dari modifikasi knee depth jump berkontribusi sendi hip 37\%, sendi knee $49 \%$ dan $14 \%$ pada sendi ankle, sedangkan dari ankle depth jump memberi kontribusi sendi hip 24\%, sendi knee 20\% dan $56 \%$ kontribusi pada sendi ankle. Dari analisis modifikasi gerakan, depth jump memberikan kontribusi power pada sendi saat melakukan gerakan melompat secara vertical (Heitman 
et.al, 2010). Sedangkan pada latihan konvensional tidak berfokus pada latihan yang dapat meningkatkan vertical jump saja, tetapi kombinasi yang membuat latihan ini kurang efektif jika tujuan nya untuk vertical jump

\section{KESIMPULAN}

Berdasarkan dari hasil penelitian yang dilakukan terhadap pemain voli Popsi Sragen dengan pemberian latihan berupa plyometric training depth jump terhadap peningkatan tinggi lompatan vertical jump didapatkan kesimpulan yaitu Ada pengaruh pada kelompok intervensi dengan pemberian latihan plyometric training depth jump terhadap tinggi lompatan vertical jump dengan nilai $\mathrm{p}<0,005$. Kesimpulan berisi rangkuman singkat atas hasil penelitian/pengabdian kepada masyarakat dan pembahasan. Ada beda pengaruh pemberian latihan plyometric training depth jump dan latihan konvensional terhadap peningkatan tinggi lompatan vertical jump dengan nilai $\mathrm{p}<0,005$. Penelitian ini mempunyai keterbatasan, yaitu hanya mengukur vertical jump pada jenis kelamin laki-laki saja, tidak membandingkan antara laki-laki dan perempuan. Di sisi lain responden kurang fokus terhadap kualitas latihan, karena responden lebih fokus pada pencapaian target repetisinya.

\section{UCAPAN TERIMAKASIH}

Alhamdulillah segala puji syukur kehadirat Allah SWT atas segala rahmat serta hidayah-Nya sehingga penulis dapat menyelesaikan skripsi dengan judul Pengaruh Pemberian Plyometric Training Depth Jump Terhadap Tinggi Lompatan Vertical Jump Pada Pemain Bola Voli.

\section{DAFTAR PUSTAKA}

Anggraini, N. D., Winarno, M. E., \& Sulistyorini. (2014). Pengembangan Pembelajaran Teknik Dasar Service Bawah Bolavoli Untuk Siswa Kelas Viii Smp Negeri 5 Malang. (service).

Arazi, H., Mohammadi, M., \& Asadi, A. (2014). Muscular adaptations to depth jump plyometric training: Comparison of sand $v s$. land surface. 6(3), 125-130. https://doi.org/10.1556/IMAS.6.2014.3.5

Biyatko Atmojo, M. (2010). Tes dan Pengukuran Pendidikan Jasmani/Olahraga.

Chelly Mohamed Souhaiel, Hermassi, S., Ridha, A., J., S., \& Roy, A. (2014). Effects Of 8-Week InSeason Plyometric Training On Upper And Lower Limb Performance Of Elite Adolescent Handball Players. 28(5), 1401-1410.

Eckert, R., \& Snarr, R. (2015). Exercise Highlight Depth Jump. (November).

Eerkes, K. (2012). Volleyball Injuries. (5), 251-256.

Grgantov, Z., And, D. J., \& Mirjana Mili ć Grgantov, Z. . et al. (2013). Evaluation Of Volleyball Techniques - Differences Between Expert And Novice Coaches. 6, 61-65.

Hansen, D., \& Kennelly, S. (2017). Plyometric Anatomy.

Harsoyo, A., \& Purnama, S. K. (2014). Pengaruh Penggunaan Media Mengajar Bola Lunak Terhadap Hasil Belajar Keterampilan Passing Bolavoli Pada Siswa Putra Kelas I Smp.

Heitman, R. J., Alabama, S., Robinson, T. L., \& College, A. S. (2010). Effects of Three Modified Plyometric Depth Jumps and Periodized Weight Training on Lower Extremity Power. 1-14.

Jaya, I. P. P., Tirtayasa, K., Muliarta, I. M., Adiputra, Luh Made Indah Sri Handari Purnawati, S., \& Griadhi, I. P. A. (2018). Ekstrakurikuler Bola Voli The Power Leg Muscle Plyometrics Than 
Volleyball Extracurricular. 8-18.

Kharisma, T. B. (2014). Pengembangan Pembelajaran Permainan Bolavoli Mini Siswa Kelas V Sdn Babadan 2 Kecamatan Wlingi Kabupaten Blitar.

Khlifa, R., Aouadi, R., Hermassi, Souhailchelly, Souhaiel, Mohamedjlid, ... Carlo. (2010). E Ffects Of A P Lyometric T Raining P Rogram With. 24(11), 2955-2961.

Lin, K. K. (2017). Applying Game Theory to Volleyball Strategy Applying Game Theory to Volleyball Strategy. 8668(May). https://doi.org/10.1080/24748668.2014.11868756

Nur Budi Handayani, SST, M. S., Dwi Susilo, M. S., Amiek Chamami, SST, M. S., Setiawan, A., \& Nugroho, S. W. (2014). Penyajian Data dan Informasi Kepemudaan dan Olahraga 201414 Januari 2016.pdf (p. 74). p. 74.

Prieske, O., Demps, M., Lesinski, M., Granacher, U., Sciences, M., \& Sciences, M. (2017). Combined Effects of Fatigue and Surface Instability on Jump Biomechanics in Elite Athletes.

Rajan, S., \& Pushparajan, A. P. . (2010). Effects Of Plyometric Training On The Development The Vertical Jump In Volleyball Players. 28(3), 65-69.

Sari, D. R. K., \& Rahayu, U. B. (2008). Pengaruh Latihan Plyometrics “ Depth Jump ” Terhadap Peningkatan Vertical Jump Pada Atlit Bola Voli Putri. 8(2), 145-149.

Sattler, T. I. N. E. S., Ekulic, D. A. S., Adzic, V. E. H., \& Ljevic, O. G. U. (2012). Vertical Jumping Tests In Volleyball: Reliability, Validity, And Playing-Position Specifics. 1532-1538.

Sattler Tine, Damir Sekulic, Vedran Hadzic, Ognjen Uljevic, A. E. D. (2012). Vertical Jumping Tests In Volleyball: Reliability,Validity, And Playing-Position Specifics. Journal of Strength and Conditioning Research, 1532-1538.

Singh, D., \& Singh, S. (2012). Effects of progressive depth jumping on vertical jump performance. $\operatorname{VIII}(3), 1915-1921$.

Ugarkovic, D., \& Jaric, S. (2001). Effects on plyometric training on jumping performance in junior basketball players. (August 2015).

Verma, C., Subramanium, L., Krishnan, V., \& Consultant, E. (2015). International Journal of Medical Research. 4(1), 7-12. https://doi.org/10.5958/2319-5886.2015.00002.8

Winarno, M. E. (2018). Buku bolavoli 2013. (January). 